\title{
EN TORNO A LA PORTADA DEL BURGUILLOS
}

\author{
Macarena Cuiñas Gómez \\ UNIVERSIDAD DE VIGO
}

En la primera mitad del siglo XVII español la portada se había constituido, tiempo ha, en uno de los apartados fijos en la impresión de las obras literarias. Si bien los incunables carecían de ella, por lo cual tenían que ser identificados con su incipit, lo que daba lugar a largas descripciones, la imprenta trajo consigo la conciencia del libro como objeto dirigido a un público al que era necesario atraer. De ahí surgió la importancia de la portada como fuente de información de la obra, al reseñar autor, título, lugar, fecha y nombre del impresor. Y llegó a concebirse como medio de propaganda del libro, de su contenido o protagonistas.

Se produjo una evolución tipográfica e iconográfica de la portada en los siglos XVI-XVII promovida por las corrientes espirituales y filosóficas. José Manuel Matilla Rodríguez trata del papel fundamental del arte en la difusión de los nuevos ideales y valores de la monarquía y la nobleza así como de las ideas contrarreformistas. En sus propias palabras el arte barroco adquiere "un 
carácter marcadamente didáctico y apologético."1 En este sentido se enmarcan muchas de las imágenes que se repetirán constantemente al inicio de los libros. Así se imprimen retratos del autor, escudos de armas de los protagonistas, orlas, enseñas religiosas, imágenes que en ocasiones se vuelven crípticas bajo el aspecto de emblemas o jeroglíficos que agudizan el interés del lector y el ingenio del autor e impresor que transmiten de manera oculta ideas o valores.

Un ejemplo plenamente barroco de nuestras letras españolas es el Fénix de los ingenios, el gran Lope de Vega. En una primera consulta a algunas de sus portadas se puede observar una evolución desde la sencillez de las Rimas sacras de 1614, que solamente aporta los datos imprescindibles con el nombre del personaje al que va dedicado el libro más una pequeña orla que encuadra las siglas religiosas IHS, hasta alcanzar una mayor complicación en la ejecución del gravado que envuelve la portada a modo de puerta monumental o frontispicio de la obra de arte que le sigue. En este último caso se encuentran La Filomena de 1621 y La Circe de 1624, en las que no faltan escudos, lemas y reproducciones escultóricas. ${ }^{2}$

El estudio minucioso de las portadas de todas las obras de Lope de Vega dadas a la imprenta constituiría tema de gran interés; me ocuparé ahora de la que preside la impresión, en 1634, de las Rimas humanas y divinas del licenciado Tomé de Burguillos. ${ }^{3}$

Se inicia con el título en un cuerpo de letra mayor, de tipo genérico, muy propio de la época, y calificado por dos adjetivos, en letra algo menor, que precisan más el contenido del libro. Ya Petrarca empleó este término de "Rimas" como título en sus Rime sparse, y fue muy popular en la literatura áurea española, así se llamaron las Rimas (1602) de Lope o sus Rimas sacras (1614), o las Rimas (1634) de los hermanos Argensola, entre otras muchas, y fue título que se prolongó hasta el siglo XIX, como por ejemplo, las Rimas de Gustavo Adolfo

\footnotetext{
${ }^{1}$ J. M. Matilla Rodríguez, "El valor iconográfico de la portada del libro en el siglo XVII y su explicación en el prólogo", Cuadernos de arte e iconografía. Revista virtual de la Fundación Universitaria española, 8 (1991), p. 1.

${ }^{2}$ Reproduzco las tres portadas, Rimas sacras, La Filomena y la Circe, al final de mi trabajo, extraídas del volumen Lírica de Lope de Vega editado por José Manuel Blecua en Madrid, Castalia, 1981. ${ }^{3}$ La imagen de la portada incluida en este trabajo ha sido extraída de la edición facsímil de la princeps elaborada por la Cámara Oficial del Libro de Madrid en 1935, centenario de la muerte de Lope. Por otro lado, cito esta y otros textos de las Rimas humanas y divinas del licenciado Tomé de Burguillos por mi edición para la editorial Cátedra, Madrid, 2008.
} 
Bécquer. ${ }^{4}$ El barroco revolucionó este concepto e incluyó bajo este epígrafe todo tipo de metros y estilos poéticos, sin que el conjunto pierda unidad estructural. Esta miscelánea constituye una de las características del Burguillos.

LosadjetivosquecalificanalsustantivoRimas, humanasydivinas, establecen la estructura binaria de este libro. Responden a dos fuerzas complementarias y en ocasiones antagónicas cuando entran en conflicto. El choque brutal entre ellas fue fuente de tormento para un Lope de Vega piadoso, espiritual, y al mismo tiempo apasionado, mundano. En muchos momentos de su vida esta dualidad, muy a su pesar, se resolvió a favor de la última tendencia. En el caso concreto del Burguillos y atendiendo solamente al número de poemas incluidos en una y otra parte, puede observarse que frente a una tirada de ciento sesenta y un sonetos, las siete silvas de La Gatomaquia, y algunas composiciones más llamadas "humanas", se encuentran las once que pertenecen al apartado de Rimas divinas.

Enlazado a este título, se presenta al autor de los versos: el Licenciado Tomé de Burguillos. Este nombre era seudónimo conocido de Lope de Vega puesto que ya lo había empleado en la forma de "El Maestro Burguillos" en las Justas poéticas celebradas en honor de la beatificación y canonización de San Isidro, patrono de Madrid, en los años 1620 y 1622. De nuevo en la misma portada se explicita otra dualidad al referir más abajo el nombre completo del verdadero autor.

Durante mucho tiempo la crítica literaria se ha ocupado de la identidad real o no de este personaje. Si bien estuvo claro desde la publicación del libro que había sido escrito por Lope de Vega, puesto que este no jugó a ocultar su nombre en ningún momento como se puede advertir en su lectura, la posibilidad de que Tomé de Burguillos hubiese existido como conocido de Lope o personaje de la época suscitó multitud de conjeturas. Se habló de Burguillos como un estudiante salmantino, un autor de romances, un religioso llamado Fray Bartolomé de Burguillos (1580-1634), un poeta toledano de coplas, Juan Sánchez Burguillos, o un loco conocido en el Madrid de la época. ${ }^{5}$

\footnotetext{
${ }^{4}$ Cfr. Y. Novo, "Sobre el marbete Rimas. A propósito de Lope, y el estatuto de la poesía lírica en el Siglo de Oro", Revista de literatura, 107 (1992), pp. 129-148.

${ }^{5}$ Cfr. A. Huarte, "Lope de Vega y Tomé de Burguillos", Revista de Filología Española, IX (1922), pp. 171-178; A. Carreño, "Los engaños de la escritura: las Rimas de Tomé de Burguillos de Lope de Vega", en M. Criado de Val (dir.), Actas del I Congreso Internacional sobre Lope de Vega. Lope de Vega y los orígenes del teatro español, Madrid, Edi-6, 1981, pp. 547-563; A. Blecua, “Juan Sánchez Burguillos, ruiseñor menesteroso del siglo XVI", en Estudios sobre el Siglo de Oro. Homenaje al profesor Francisco Ynduráin, Madrid, Editora Nacional, 1984, pp. 69-85; F. A., Lapuente, “Más sobre los seudónimos de Lope de Vega", en M. Criado de Val (dir.), Actas del I Congreso Internacional sobre Lope de Vega. Lope de Vega y los orígenes del teatro español, Madrid, Edi-6, 1981, pp. 657-669.
} 
Lo interesante es el grado de estudios que Lope le otorga a su seudónimo: licenciado, nivel que él hubiera deseado para sí pero al que no tuvo acceso. Quizás pensaba que con este grado habría encajado perfectamente en el mundo de la intelectualidad de su tiempo, anhelo que persiguió hasta el fin de sus días.

Pero lo realmente importante del personaje Burguillos lo constituye la manera en que Lope lo creó y el fin para el cual lo hizo. Dotó a esta entidad ficticia de una realidad a base de datos acerca de su vida, su físico y su carácter, y lo hizo con una intención lúdica, puramente literaria, que le permitía distanciarse de su propia poesía en una suerte de enajenación burlesca y juguetona. ${ }^{6}$ Quizás también esta circunstancia le facilitó la crítica de los males de su tiempo, pero no parece que a estas alturas de su vida, pasados los setenta años, cuando los premios que había de alcanzar los poseía ya y se había despedido de los que nunca le llegarían, le importase mucho atenuar sus palabras bajo un seudónimo.

Por el momento se apostilla al título la siguiente expresión: "No sacadas de biblioteca ninguna (que en castellano se llama librería) sino de papeles de amigos y borradores suyos." El libro se presenta como una recopilación hecha entre los papeles de los amigos de Burguillos y sus propios borradores, lo que convierte a Lope de Vega en un mero compilador de versos de otro poeta. Desde la portada se establece una relación ficticia entre estos dos personajes: uno escribe y el otro reúne la obra del primero con la intención de imprimirla para que sea difundida entre el gran público. Como señala Cayetano Alberto de la Barrera ${ }^{7}$ la frase "no sacadas de biblioteca ninguna (que en castellano se llama librería)" supone una alusión satírica dirigida contra don José Pellicer Salas y Tovar, que acababa de dar al público las Obras de Anastasio Pantaleón de la Ribera (1631), estampando en la portada: "Salen a luz de la biblioteca de D. Joseph Pellicer". Véase el desprecio burlesco del cultismo "biblioteca" frente al término "librería" que prefiere por sencillo. En esta expresión, "que en castellano se llama", subyace la polémica antigongorina, en la que Pellicer

\footnotetext{
${ }^{6}$ Como ya he citado más arriba Lope había dado a conocer a Tomé de Burguillos en las Justas poéticas en honor de San Isidro en los años 1620 y 1622 en Madrid y construye una semblanza de su persona en el "Advertimiento al señor lector" de estas Rimas de Tomé de Burguillos, así como remite a este personaje en muchos poemas del mismo libro, como en los sonetos 28, 115, 137, 163.

${ }^{7}$ C. A. de la Barrera, Nueva biografía de Lope de Vega, Biblioteca de Autores españoles, Madrid, Atlas, 1973, I, p. 325.
} 
tomó parte como seguidor acérrimo del gran poeta cordobés, y que identifica el castellano o el romance con la expresión popular y sencilla que Lope reivindicaba como culta, y el griego con la expresión retorcida, cultista, de los seguidores de Góngora, iguales en la oscuridad de la expresión pero carentes del talento del genio.

En este sentido Lope incluye estas palabras en el prólogo "Advertimiento al señor lector" cuando describe al maestro Tomé de Burguillos:

Fue general en las Humanas y no particular en alguna ciencia, a cuyas noticias le ayudaron las lenguas comunes que fuera de la griega sabía y que nunca quiso estudiar porque decía que hacía más soberbios que doctos a muchos que apenas pasaban de sus principios.

Ejemplo grande para tantos que se prometen el primero, despeñados de una lengua bárbara a la eterna escuridad de sus escritos, como algunos que, faltándoles opinión para sí, piensan que la pueden dar a los otros, y olvidados de la verdad hacen príncipes de mentira.

si el estilo es más castellano que culto, perdonen los que lo son, porque este poeta decía que como duran poco las novedades, andando el tiempo caerían los hombres en la verdad y se volvería a usar la propia lengua.

E insiste en esta cuestión en sonetos como el 66 titulado “Díjole una dama que le enviase su retrato" en el que después de una descripción burlesca de sí mismo termina diciendo:

tengo con ropa limpia el nacimiento, la cara en griego y en romance el alma.

Destaca su origen cristiano, limpio de sangre, y cómo el exterior es confuso, por feo, pero el interior, lo más importante, es sencillo y bello. Griego y romance, como hemos visto, metáforas de la poesía de corte gongorino que Lope desprecia y de la poesía clara que defiende.

También se encuentra en esta línea el soneto 147 de estas Rimas de Tomé de Burguillos que se titula "Responde a un poeta que le afeaba escribir con claridad, siendo como es la más excelente parte del que escribe": 
Livio, yo siempre fui vuestro devoto, nunca a la fe de la amistad perjuro, vos en amor como en los versos duro, tenéis el lazo a consonantes roto;

si vos imperceptible, si remoto, yo blando, fácil, elegante y puro, tan claro escribo como vos escuro, la vega es llana y intrincado el soto.

También soy yo del ornamento amigo, sólo en los tropos imposibles paro, y deste error mis números desligo;

en la sentencia sólida reparo porque dejen la pluma y el castigo, escuro el borrador y el verso claro.

Por otro lado, la fructífera unión entre un poeta y su compilador recuerda y parodia las establecidas entre grandes humanistas y sus comentaristas, como Garcilaso de la Vega y Fernando de Herrera, Fray Luis y Quevedo, o lo que el mismo Pellicer hizo con la poesía de Góngora. El ejemplo de este último rebaja el noble oficio de los otros y el caso de Lope con respecto a Burguillos consuma la parodia. Pero no se burla de la tarea del comentarista erudito, que tiene en altísima estima, solamente de la capacidad de otros para este trabajo e, incluso, de su propia pretensión de creerse comparable a ellos.

La portada incluye a continuación el nombre del personaje al que se ha dedicado el libro: “Al Excelentísimo Señor Duque de Sesa, Gran Almirante de Nápoles". Don Luis Fernández de Córdoba, era sobrino-nieto de don Gonzalo Fernández de Córdoba, tercer duque de Sesa, nieto del Gran Capitán. Nacido en Baena el 25 de enero de 1582 fue el heredero de la casa de Baena y Sesa. Durante su permanencia en Roma completó su instrucción estudiando Humanidades. Se casó con doña Mariana de Rojas, de la ilustre casa de Poza en 1599. A la muerte de su padre sus títulos y mayorazgos pasaron a él: conde de Cabra, sexto duque de Sesa, cuarto de Baena, Vizconde de Iznájar, señor de Rute, Zambra, doña Mencía y Alcaudín, quinto duque de Soma, conde de Palamós y de Oliveto, Barón de Bellpuig, Liñola y Calonge, cabeza y jefe de una de las casas más ricas, poderosas y linajudas que entonces contaba la monarquía española. Fue desterrado de la Corte todo el invierno y parte de la primavera de 1611-12. En 1614 alcanzó del monarca el Almirantazgo de Nápoles. Fue desterrado por 
segunda vez en Baena (1627-8). Su vida transcurrió, según los testimonios de época, en la holganza y poltrona de la mayoría de los poderosos de su tiempo. Estableció amistad con Lope de Vega en 1605, el cual fue su secretario durante el resto de su vida. Presidió y costeó el sepelio del Fénix en agosto de 1635 en Madrid. El duque falleció el 14 de noviembre de 1642.

Bajo el nombre del personaje al que se dedica el libro se inscribe el del que lo dedica, normalmente identificado con el autor, en este caso: "por frey Lope Félix de Vega Carpio del hábito de San Juan". Por lo tanto, en la portada ya se explicita el nombre completo de Lope de Vega, editor de las Rimas. El título de Frey que Lope ostenta es consecuencia de recibir el honor de Doctor en Teología por el Collegium Sapientiae otorgado por el Papa Urbano VIII en correspondencia a la dedicatoria que el Fénix le dirigió en la publicación de su Corona trágica (1627). Así mismo le concedió la Cruz de San Juan, de ahí que la portada rece "del hábito de San Juan", siendo el "hábito" la insignia con la que se distinguían las órdenes militares. Lope gustaba mucho de ostentar este honor que buscó halagando al Sumo Pontífice con su obra y que le permitía una distinción, si bien no de tipo económico, sí de índole social.

Inmediatamente debajo de estas palabras se inserta una imagen, en este caso se trata de un motivo heráldico propio de la portada de un libro del denominado estilo español. Representa el escudo de armas de don Luis Fernández de Córdoba que también reprodujo al inicio de la Expostulatio Spongiae (Madrid, 1618) y, por supuesto, en las portadas de esta última etapa, como en El castigo sin venganza (Madrid, 1634) y La Vega del Parnaso (Madrid, 1637). Esta ilustración remite a la persona a la que se dedica la obra, ensalza sus cualidades, su nobleza expresada a través de sus armas, y cómo no, su valeroso linaje que aglutinó en una misma familia ducados, condados, marquesados y baronías. Este escudo expresa el agradecimiento de Lope, quizás su servilismo para con el duque, ${ }^{8}$ pero también el enaltecimiento de unos valores de nobleza y valentía con los que se sentía identificado y le acercaban al poder moral y económico de su época.

En la edición original este escudo se encuentra en blanco y negro de manera que se pierden los matices de los esmaltes, muy importantes en una descripción heráldica como la que paso a realizar. Aún así menciono aquellos

\footnotetext{
${ }^{8}$ Para cuestiones relativas a las relaciones entre Lope y el duque de Sesa cfr. A. González de Amezúa, Epistolario de Lope de Vega, IV vols., Madrid, Real Academia Española, 1989.
} 
colores que hoy pueden conocerse porque siguen siendo seña de determinados lugares de España.

El contorno exterior de este escudo de armas posee una clara influencia francesa y es usado en los dibujos en los que se busca facilidad de representación. El campo está dividido en varios cuarteles resultado de las particiones hechas para poder representar en un solo escudo todos los linajes relativos a las alianzas establecidas entre familias. Tenemos, por lo tanto, una suma de escudos representados en cada cuartel.

En un principio se trata de un escudo partido, esto es, dividido perpendicularmente en dos partes iguales cada una de las cuales contiene a su vez particiones irregulares. La parte diestra del escudo muestra un cuartelado en cruz, esto es, una superposición de las particiones partida y cortada. La parte siniestra del escudo muestra un terciado en palo, esto es, división del escudo verticalmente en tres partes del mismo ancho.

He aquí la descripción de todos los cuarteles de este escudo. El primer cuartel de la parte diestra acoge un escudo cuartelado en aspa, $1 .^{\circ}$ y $4 .^{\circ}$ en campo de oro cuatro palos de gules que representan el reino de Aragón, y $3 .^{\circ}$ y $2 .^{\circ}$ pueden ser armiños, puesto que no se distingue en el dibujo. El segundo cuartel representa las armas de Córdoba: escudo cortado, $1 .^{\circ}$ en campo de oro, tres fajas de gules, y 2. ${ }^{\circ}$, en campo de plata Rey moro preso con cadenas al cuello, moviente del flanco siniestro. Fue añadido al escudo de armas en 1483, al caer preso el rey Boabdil de Granada a manos de Don Diego Fernández de Córdoba. El tercer cuartel de esta parte diestra del escudo: en campo de oro, cuatro fajas de gules. Y el cuarto cuartel acoge un escudo partido: 1 . $^{\circ}$ en campo de oro, tres palos de gules (Aragón) y el $2^{\circ}$ no se distingue. La parte siniestra del escudo muestra un terciado en palo: $1^{\circ}$ en campo de oro tres palos de gules (Aragón); 2. ${ }^{\circ}$, escudo cortado con los símbolos del castillo, primer cuartel, y el león, segundo cuartel (reinos de Castilla y León); y $3 .^{\circ}$, escudo cuartelado en aspa, $1 .^{\circ}$ y $4 .^{\circ}$ en campo de oro cuatro palos de gules, y $3 .^{\circ}$ y $2 .^{\circ}$, águilas, escudo que representa el reino de Sicilia.

Este complejo campo del escudo de armas del duque de Sesa refleja los títulos nobiliarios que poseía, que abarcaban parte del territorio español (Andalucía, Aragón, Cataluña) e italiano.

En cuanto a los adornos exteriores de este escudo está timbrado por una corona de duque de oro engastado el círculo de pedrería y con un realzado de florones, también dos perlas vistas, lo que caracteriza a un tipo específico de duque (belga y holandés). Sobre la corona, penachos, que normalmente 
rematan el casco. El empleo de banderas acoladas al escudo lo encontramos en la heráldica militar y revelan la dignidad del poseedor del mismo, el cual dispone su colocación a su capricho como el resto de los signos exteriores del escudo. Estos adornos exteriores pertenecen a la persona que en el momento es propietaria del escudo y no se heredan.

La portada remata con el pie de imprenta. Se especifica la fórmula "con privilegio" que indica que este libro cuenta con la autorización necesaria para ser impreso y vendido en exclusividad por un tiempo concreto. Este era un requisito de carácter obligatorio. A continuación se recoge el lugar, el impresor y el año de publicación. En este caso se imprimió en Madrid, en la Imprenta del Reino, en 1634. La Imprenta del Reino funcionó en Madrid desde 1628 hasta muy avanzado el siglo con una actuación paralela a la de la Imprenta Real pero sin relación con ella. Las más importantes obras salidas de sus prensas son: A la muy antigua, noble y coronada villa de Madrid, historia de su antigüedad, nobleza y grandeza de Jerónimo de la Quintana (1629), Lecciones solemnes a las obras de Don Luis de Góngora de José Pellicer de Ossau y Tovar (1630), El privado cristiano de José Laínez (1641), el Arte de los metales de Álvaro Alonso Barba (1640) y una edición de Geometría y trazas pertenecientes al oficio de sastres de Martín de Andújar (1640).

El último dato reseñado en la portada del Burguillos es el nombre del impresor: Alonso Pérez, que consta como "Librero de su Majestad". Este costeaba y cuidaba de la impresión del libro, de ahí la expresión que le precede "A costa", puesto que era él el que adquiría el privilegio y se la encargaba a un tipógrafo. En la inmensa mayoría de los casos detrás del nombre consta el título de "mercader de libros", lo que demuestra que fueron los libreros los realizadores habituales de esta tarea. Alonso Pérez era amigo íntimo de Lope de Vega, y padre de su también amigo Juan Pérez de Montalbán, el autor de la Fama póstuma. Tanto es así que fue él quien costeó el entierro de Marta de Nevares (1632), muerte tan dolorosa para el poeta. Nombrado librero del rey, fue uno de los grandes editores de la primera mitad del siglo XVII. Su mayor actividad editorial se desplegó desde 1602, año en que coeditó con Andrés López La Diana de Jorge de Montemayor, hasta 1646, en que reeditó El diablo cojuelo de Luis Vélez de Guevara. Murió el 22 de diciembre de 1647. En cuanto a su relación editorial con Lope de Vega comienza con una reedición de las Rimas (1604), otra de la Arcadia (1611), la primera edición de los Pastores de Belén (1612), las Rimas sacras (1614), el Triunfo de la fee en los reinos del Japón (1618), la 
Justa poética... (1620), la Filomena (1621), la Circe (1624), los Triunfos divinos (1625) y en 1627, dos obras, Corona trágica y los Soliloquios amorosos de un alma a Dios, edita las partes IX, XI, XII, XIII, XV, XVI, XVIII, XIX, y XX de comedias, en 1632 La Dorotea, en 1634 las Rimas humanas y divinas del licenciado Tomé de Burguillos, $\mathrm{e}$ incluso, muerto ya Lope, en 1636, colabora y edita el homenaje que su hijo Juan Pérez de Montalbán tributa a su muerte en la Fama póstuma.

Sumada a esta faceta de editor, Alonso Pérez desarrolló la de mercader de libros en su librería de la calle de Santiago en pleno centro de Madrid. Parece que se instaló en este lugar hacia 1602-1607 y allí vivía en 1616. Su librería era considerada como una de las más surtidas del momento. ${ }^{9}$ Esta profesión abarcaba en la época dos ámbitos: el de la creatividad, en su labor como editor de textos literarios cuyas ediciones costeaba y cuidaba con mimo, y el del comercio, en su trabajo como mercader de libros a los que buscaba un rendimiento mercantil.

Las Rimas humanas y divinas del licenciado Tomé de Burguillos (1634) de Lope de Vega se inician con una portada del tipo del barroco español, clasificada así por las partes de que consta y la inclusión de una ilustración, en este caso, de carácter nobiliario. Un estudio detenido de ella revela que constituye un elemento literario más de la obra, en el que se anuncia el contenido y el tono de la misma, se establece un juego de dobles entre lo humano y lo divino y el seudónimo y el verdadero autor, se ironiza y parodia acerca del comentario y compilación de los versos de un poeta hecho por otro, se lanzan dardos envenenados contra los enemigos literarios, se alimenta la crítica al estilo oscuro frente al claro y sencillo, y se desvela la personalidad literaria e íntima de Lope de Vega: el gran talento poético que ensalza el noble linaje de otro, su mecenas, para asegurarse el sustento y asimilarse, de alguna manera, a los poderosos, el hombre que anhela ser reconocido y presume de títulos honoríficos otorgados por el Papa, esto es, el Frey y el hábito de San Juan.

Por lo tanto, esta portada compendia buena parte de los asuntos y temas que se desarrollan a lo largo del libro que precede. En ella destacan los personajes más importantes y despunta el tono lúdico que envuelve todo el volumen. Sin duda esta portada responde a un requisito del libro áureo español puesto al servicio del enorme talento imaginativo del Lope creador literario.

\footnotetext{
${ }^{9}$ Para los datos acerca de Alonso Pérez, cfr. A. Cayuela, Alonso Pérez de Montalbán. Un librero en el Madrid de los Austrias, Madrid, Calambur editorial, 2005.
} 


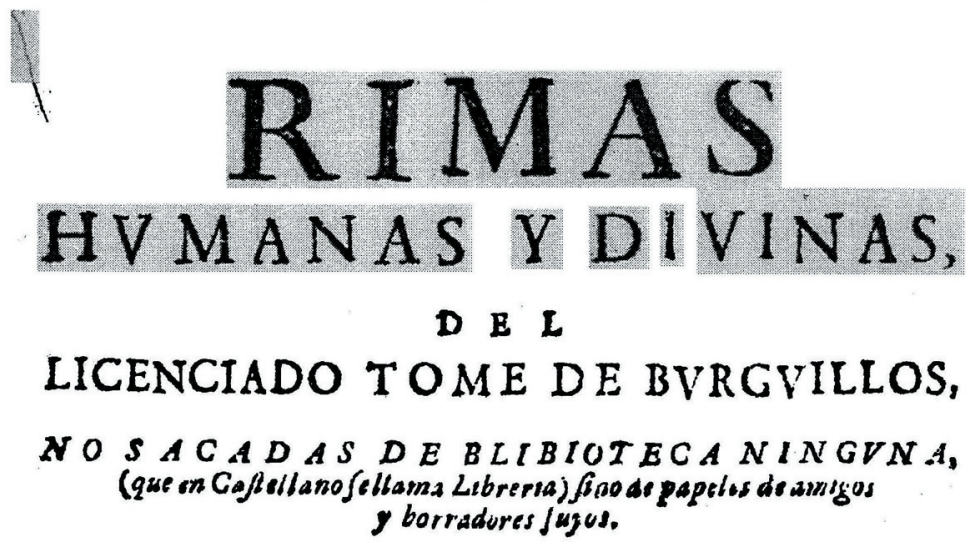

AL EXCELENTISSIMO SE NOR DV QVE DE Selfa, Gran Almirante de Napoles.

POR FRET LOPE FELTIDE VEGA CARPIO dist ausiso at San liwen.

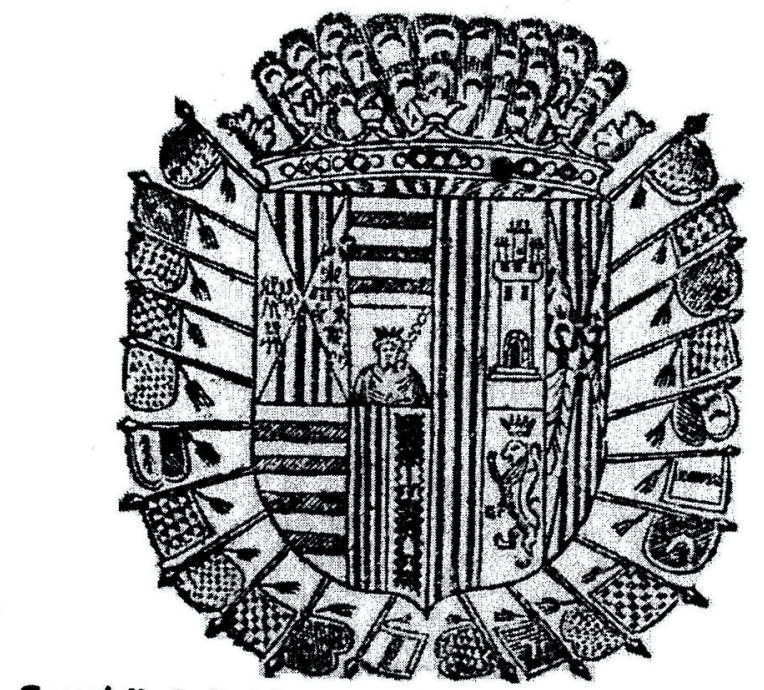

Coapai xilegio. En Madrid en la lmprenta del Reyno, Ańo 1634.

A cofta de Alonjo Perce, Librere deju Mageflad. 


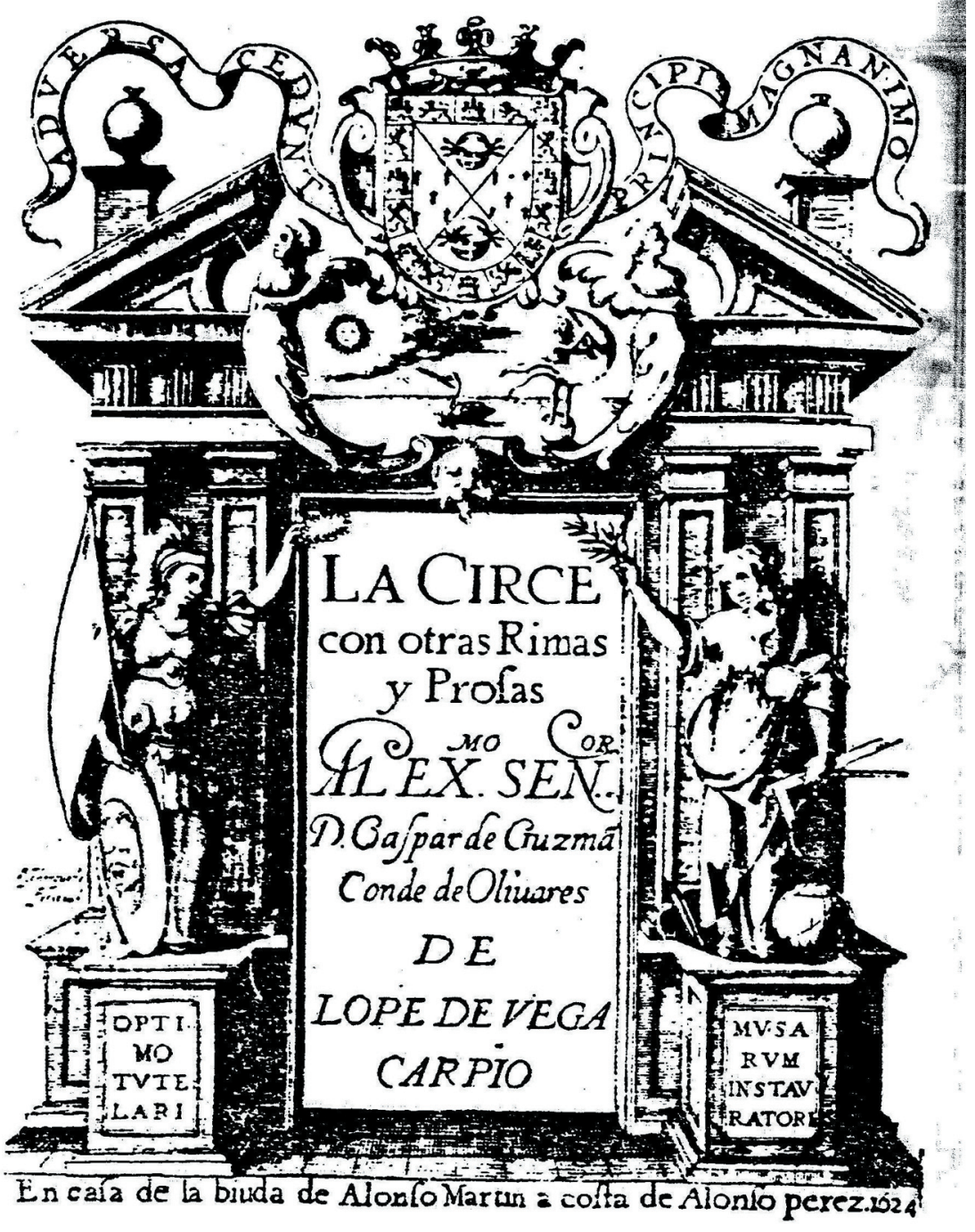




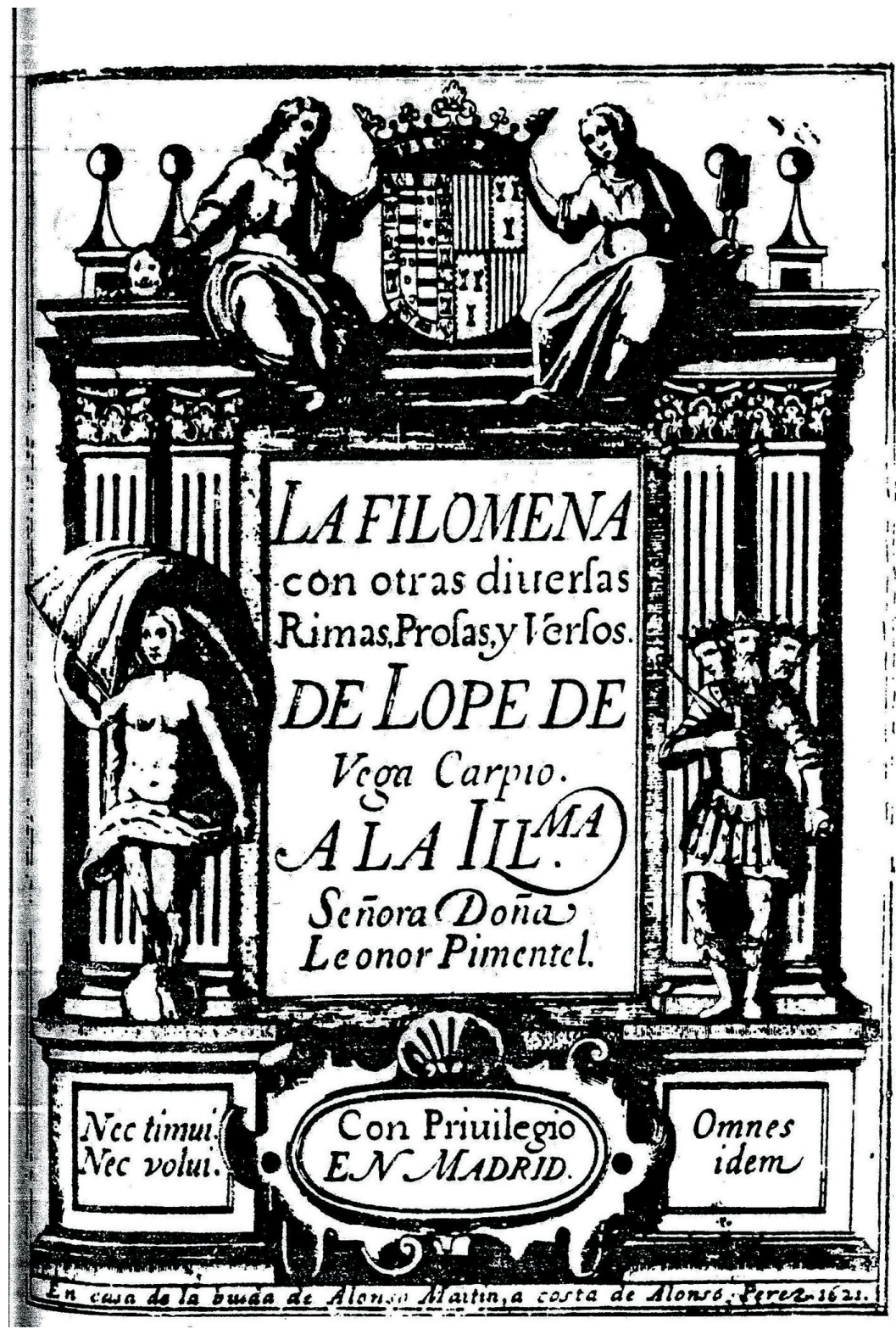


RIMAS

$S A C R A S$.

PRIMERA PARTE

De Lope de V ega Carpio, Cle rigopresbytero.

DIRIGIDAS A L PADRE Fray Martin de fan Cirilo Religióo décalco de nueftra Señora del Carmea:

(2)

Ano

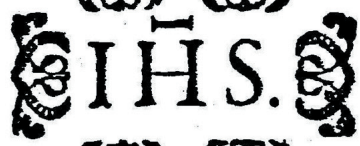

1614.

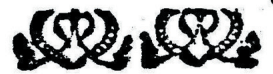

Con privilegio de Castilla y Asagon.

Por la viuda de Alonso Martin.

A cofta de Alonfo Perez mercader de libros. 